\title{
Las ilustraciones en los medios impresos contemporáneos: hibridaciones estéticas e imágenes complejas
}

\author{
Laan Mendes de BARROS \\ Universidade Metodista de São Paulo \\ laan.barros@metodista.br \\ Márcia Rodrigues da CostA \\ Universidade Metodista de São Paulo \\ marciarcosta13@gmail.com
}

Recibido 24 de febrero de 2014

Aceptado: 8 de septiembre de 2014

\section{Resumen}

En este artículo se analiza la presencia de la ilustración en la prensa a partir de los conceptos de hibridación e imagen compleja, utilizando la fenomenología de la experiencia estética y de la hermenéutica. Se conceptualizan elementos del lenguaje y la iconografía de los procesos de impresión y se analizan los vínculos entre las imágenes estéticas e hibridaciones complejas en la comparación entre el significado contenido en el objeto estético y el significado producido en la percepción estética, un cambio en el medio-mensaje de mediaciones culturales que caracteriza a los procesos de recepción. Se presentarán principalmente las formulaciones teóricas y metodológicas de Josep Maria Català y Néstor García Canclini.

Palabras clave: hibridación, ejemplo, imagen compleja, la hermenéutica, estética.

\section{The illustrations contemporaries in the print media: aesthetic hybridizations and complex images}

\begin{abstract}
This article discusses the presence of the illustration on the press from the concepts of hybridization and complex image, using the phenomenology of aesthetic experience and hermeneutics. Conceptualizes elements of language iconographic and printing processes and discusses links between aesthetic and complex images hybridizations, the confrontation between the meaning contained in the aesthetic object and meaning produced in aesthetic perception, by a shift from medium-message to the cultural mediations that characterize the processes of reception. The theoretical and methodological formulations of Josep Maria Català and Néstor García Canclini are here mainly present.
\end{abstract}

Keywords: hybridization, illustration, image complex, hermeneutics, aesthetics.

\section{Referencia normalizada}

BARROS, Laan Mendes de y COSTA, Márcia Rodrigues da (2015): "Las ilustraciones en los medios impresos contemporáneos: hibridaciones estéticas e imágenes complejas". Estudios sobre el Mensaje Periodístico. Vol. 21, Núm. 2 (julio-diciembre), págs.: 943-951. Madrid, Servicio de Publicaciones de la Universidad Complutense.

Sumario: 1. Introducción - Ilustración. 2. La prensa y el arte en tiempos de hibridación cultural. 3. Una mirada compleja sobre las imágenes. 4. Referencias bibliográficas. 


\section{Introducción - Ilustración}

La presencia de la ilustración en la prensa desde su propia génesis se produce en diferentes sistemas de impresión que se basan en la experiencia de los grabadores. Tomemos, por ejemplo, la creación de la tipografía, el sistema de tipos móviles de Johannes Gutenberg a mediados del siglo XV, que parte de la idea del alto relieve ya presente en el grabado.

La ilustración a la que nos referimos se aplica al universo específico de las artes gráficas. Se puede reforzar, repetir, subrayar y ampliar el significado del texto, criticarlo, añadir algo, anticipar o anunciar el contenido verbal, "afirmar la expresión artística" y ganar una importancia tal que su presencia puede superar el texto escrito e incluso eximirlo, explica Gilmar Hermes (2005), que investigó la presencia de la ilustración en la prensa impresa brasileña. Mientras que el autor afirma que la ilustración aparece como una forma narrativa que pretende hacer frente a la realidad teniendo en cuenta el carácter poético que el propio acto de narrar asume, por otra parte recuerda que la ilustración a veces no es capaz de describir el texto.

La ilustración fue tomada en los últimos tiempos como algo que sólo acompaña, agrega la información y/o adorna un texto escrito siguiendo una lógica funcionalista que asigna a la imagen una función de complemento. Contrariamente a la imagen basada en el realismo explícito, una de otro tipo fue estimulada por la imaginación. En los siglos XVI y XVII el ilustrador francés Geoffroy Tory creó un "todo estético" de los elementos de la página impresa -gráfico, texto e imágenes- recuerda Milton Nakata (2010: 72). La experiencia de dar al espacio para la difusión de la poesía una apreciación estética, de acuerdo con Ana Guzmán Mannarino, está presente a finales del siglo XIX:

El uso del espacio de la página como medio de expresión se remonta a las experiencias de algunos escritores de finales del siglo XIX, como Lewis Carroll, y especialmente Stéphane Mallarmé. En Un coup de dés (1897), la disposición espacial contribuyó a la significación, lo que indica pausas, silencios y connotaciones, lo que interfiere en la temporalidad del poema. Se utilizó el espacio con el fin de deconstruir la linealidad, añadiendo a la sucesión de palabras el tiempo simultáneo e indefinido de las múltiples posibilidades de lectura.

Por lo tanto, la ilustración puede ser desde el punto de vista de la explicación o de la comprensión. En el primer caso, gana el carácter descriptivo, que pretende darle una función de objetividad, muy ligada al concepto de la comunicación como la transmisión. Aquí se valora la dimensión técnica de las artes visuales como la comunicación visual. En el segundo caso, conserva su dimensión estética, su libertad simbólica y apertura a la experiencia de la percepción.

En algunas aplicaciones mediáticas, la ilustración/imagen asume la dimensión técnica del arte visual, como en el caso de la infografía que pretende aclarar la información compleja en el espacio de texto, que revela cómo la comunicación visual, la naturaleza explicativa y didáctica de la ilustración. “¿Quieres que dibuje?”, dicen los jóvenes. Esta expresión popular contemporánea refleja ese carácter explicativo y didáctico de la ilustración en la prensa. Pero no sólo se trata del fortalecimiento del dis- 
curso textual, anexo, suplemento, con una única condición y función objetiva ligada a la estrecha concepción de la comunicación como transmisión, pues preserva su dimensión estética, su libertad simbólica y la apertura a la experiencia de la percepción. A veces, en la prensa, la imagen tomó el papel de transformar la realidad en otra forma de expresión dotada de múltiples posibilidades hermenéuticas, enriqueciendo el campo de significado e interpretación. Al ocupar una zona fronteriza entre la comunicación y el arte -informa, comunica-, pero sin limitarse a tales dimensiones, el gráfico conserva la identidad artística y la libertad de expresión.

En medio de la proliferación de las técnicas y tecnologías, cabe pensar cuales son las posibilidades de la imagen / gráfico en los medios de comunicación contemporáneos. ¿Cómo analizar las imágenes contemporáneas de los periódicos impresos a partir de nuevos marcos teóricos?

\section{La prensa y el arte en tiempos de hibridación cultural}

La presencia de las artes visuales en los medios de comunicación contemporánea es el resultado de un proceso de hibridación entre el arte y el periodismo característica de la complejidad de la comunicación. En los suplementos culturales las mezclas crean nuevos lenguajes, mensajes, formas de entretenimiento e interacción. Elementos de características poco armónicas coexisten en un espacio donde los bienes culturales son a la vez comerciales y artísticos, populares y clásicos, tradicionales y modernos, superficiales y sofisticados, conservadores y experimentales, informativos y de entretenimiento, masivos y de consumo segmentado, y sirven a los intereses negocio, comercialización, alternativos y comunitarios. Los medios de comunicación son integrados y apocalípticos, afirma Arlindo Machado (2004: 14). Por lo tanto, la hibridación genera muchas discusiones sobre el texto y el contexto de la producción, la objetividad y la subjetividad y la autonomía del sujeto y productor receptor. Abre espacio para pensar la dimensión estética de los medios de comunicación y la dimensión artística de la comunicación, y promueve el diálogo entre interdiscipliariedad, Comunicación, Arte, Estética y Sociología.

Según Néstor García Canclini (2008: xix), las hibridaciones son "procesos socioculturales en los que estructuras o prácticas discretas, que existían por separado, se combinan para generar nuevas estructuras, objetos y prácticas". Al atenuar las diferencias entre los distintos elementos culturales, se obtiene un tercer elemento, híbrido, que conserva las características de cada uno de los que contribuyeron a su formación. Se debe poner más atención al proceso de las mezclas con el fin de identificar a las ganancias y pérdidas de la hibridación, apunta García Canclini (2008).

La hibridación transformó el estatuto del arte y la comunicación. Por lo tanto, una pintura, al ocupar el espacio (medio), tradicionalmente ocupado por el texto, al igual que el libro, deja de ser pintura y se convierte en su ilustración, afirma Josep Català (2011: 5). Desde esta perspectiva, pensamos las artes visuales a partir de la concepción original de la estética, en connotaciones crítico-materialistas, como "sentir con los sentidos", según Santaella (2007: 254), una ciencia de los sentidos que, en la contemporaneidad, establece relación con la vida cotidiana y con los más diversos lenguajes, además de las artes. 
La discusión sobre la hibridación entre el arte y la prensa se refiere a la discusión sobre el fin del aura, causada por la reproducción de los bienes culturales en los medios de comunicación masivos. Sin embargo, Walter Benjamin (1900: 222) llevó el debate más allá del ámbito de la industria cultural, y señaló que el arte siempre ha sido capaz de reproducirse, tales como la práctica de copiar pinturas. Desde la modernidad, surgen cada vez más obras cuya naturaleza es muy reproducible, dijo Benjamin.

La reproducción técnica afectó el dominio de la tradición y el objeto (obra) ganó actualidad, pudiendo ser visto o escuchado varias veces. Si la estética clásica tenía como referencia el valor de culto (la preservación de cuestiones como la aureola, la autenticidad, la originalidad, la belleza), en la estética de la industria cultural se acentúa el valor de exposición de la obra. Más "independiente" que la original, la reproducción técnica podría ser transportada "a situaciones en que el documento original jamás se podría encontrar”, acercándose y ganando valor de consumo. Ha cambiado la forma de sentir y percibir el arte conforme pasó a atender una necesidad del espectador, ya que, como dice Benjamin (1990: 227-228), "la exigencia de las "masas" de acercarse a las cosas "espacial y humanamente", y tienden a aceptar las reproducciones y "despreciar el carácter de lo que se da una sola vez." El estatuto de la imagen se transformó:

La reproducción del objeto, conforme a lo dispuesto por el periódico ilustrado o una revista semanal, es, sin duda, muy diferente de una simple imagen. La imagen asocia tan de cerca las dos características de la obra, su singularidad y su duración, mientras la fotografía combina dos características opuestas: las de una realidad difícil de alcanzar, pero que se puede jugar indefinidamente (Benjamin, 1990: 228).

Al incluir la ilustración, la prensa, por lo tanto, contribuyó a los cambios en el arte y la experiencia estética, generando debates sobre las relaciones entre el arte, la cultura y la comunicación.

La hibridación de lenguajes sugiere que la relación entre el texto y la imagen es, en sí, compleja. Entre las dos dimensiones semióticas se da un juego dialéctico, a veces complementario, a veces polifónico, pues los dos lenguajes se mueven claramente en el proceso de creación y lectura. Mientras que el texto sigue los códigos más restringidos, la imagen aparece más claramente, con signos analógicos. La lectura del texto requiere la decodificación del lenguaje, compuesto de palabras formadas por los dígitos alfanuméricos de un proceso deductivo más abstracto y normativo. Se necesita saber el idioma usado, el vocabulario y la estructura gramatical, en un análisis sintáctico-semántico.

En el caso de la imagen, la recepción es un ejercicio cognitivo distinto mediante un proceso inductivo de articulaciones lógicas más concretas. La representación está vinculada a la cosa representada, por analogía, y las posibilidades de interpretación dependen más de las mediaciones culturales experimentadas en la recepción y producción de sentidos. La imagen utilizada como ilustración mantiene esta dinámica abierta, y al mismo tiempo concreta, en su producción y disfrute. La imagen comunica, pero no se limita a esto, pues se ofrece la interpretación especular al espectador provocándole sensaciones, más que la pura comprensión; comunica, no en la clave de la transmisión, sino 
en al de compartir. Por lo tanto, la imagen debe ser vista bajo una mirada compleja al mismo tiempo que debe visibilizar la complejidad de la era contemporánea.

\section{Una mirada compleja sobre las imágenes}

No es de extrañar que el fotoperiodismo impregnara la imagen de la función de mero ilustrador de la realidad, de pretensión de objetividad, herencia del cientificismo positivista, ejemplo de que en los medios impresos la información es fruto de convenciones y mecanismos culturales, según Dulcília Schroeder Buitoni (2012), quien recuerda que la imagen no es el registro de lo real si no de la verdadera transformación de lo real. Josep Català hace hincapié en la influencia de los mecanismos culturales a la hora de recurrir al mito de la ilustración para explicar la función del texto como adorno -la posibilidad de visualizarlo, sería una influencia de la Ilustración-, que se refiere a la proyección luz sobre la realidad en la búsqueda del esclarecimiento de ideas. Esta construcción de la función ilustrada e ilustrativa de la imagen, sometida a un "simple artefacto mnemotécnico", se naturalizó.

Citando a Bernard Stiegler, Català (2011: 47) recuerda que la estética del capitalismo ha creado formas de vida proporcionando imágenes técnicas con una determinada intencionalidad. En una ecología tecnoindustrial en el que la técnica es la principal narrativa y plataforma artística del siglo XX, el medio no es inocente porque se interpone entre nosotros y la realidad, "por lo que no hay imágenes neutrales, y mucho menos si estas imágenes surgen de un marco tecnológico que cumple ciertas funciones" (Catalá, 2011: 48). Si la imagen técnica surgió paralelamente a los medios de comunicación industrial (cine, televisión, ordenador, etc), producida por un dispositivo tecnológico, se recomienda pensar cada imagen en su "medio" porque "cada imagen pertenece a un entorno determinado y es el producto de una técnica concreta". En este caso, la denominación de "medio" se refiere a algo "en relación con un entorno, una ecología tecnoinformativa, tecnopersuasiva tecnológica o representativa" (Catalá, 2011: 33).

Buitoni (2012: 15) advierte que "la facilidad tecnológica no ha contribuido a un uso más creativo y expresivo" ni para generar conocimiento, por ejemplo: el uso de la fotografía en el periodismo en línea y la hegemonía y la banalidad de la imagen que la televisión sugiere ¿Cómo interfieren las condiciones de producción en el ajuste de los formatos verbales y visuales que circulan en los medios de comunicación?

Pero Català (2011) advierte que debemos prestar más atención a las imágenes que en el camino "que se supone que nos lleva a las imágenes", evitando "la fenomenología visual de las principales explicaciones teóricas articuladas por la cultura de forma totalitaria y excluyente, como por ejemplo el del marxismo y de la lingüística, donde la imagen sirve más como ejemplo de los supuestos teóricos". Català sugiere que "la aproximación de la imagen canalizada por estas disciplinas debe ocurrir de manera subsidiaria" porque la imagen no es simplemente el resultado de una acción persuasiva. Además de su carácter técnico, con carácter ilustrativo o mimético -copia simplificada o mera reproducción de la realidad- la imagen puede ser sintomática y compleja, revelando aspectos de la sociedad. Nos recuerda que la fenomenología de los medios de comunicación rebasa los límites de la obra o imagen. "Esa obra tiene, 
sin embargo, su fenomenología particular, que no puede ser simplemente reducida a las propiedades del medio, así como las características generales de esta, su modo de exposición, no pueden deducirse sólo a partir del alcance de la tecnología pertinente".

Es necesario entender estos niveles por separado, a pesar de que interactúan juntos. Soporte y contenido deben ser analizados en conjunto (Catalá, 2011: 33-34). "En primer lugar necesitamos saber examinar directamente la imagen, explorar su fenomenología antes de empeñarla en una operación que ya tiene sus propios intereses particulares e ignora las peculiaridades de lo visual" (p. 31). Evitando la visión mecánica/tecnopersuasiva -es el caso de autores como Guy Debord, que condenan la imagen desde una concepción política e ideológica fatalista de la experiencia estética-. Català (2011: 17) defiende la ecología de lo visible y sus diferentes manifestaciones, para que podamos entender cómo piensan las imágenes para saber lo que contienen, sugieren, emocionan y cómo proporcionan procesos reflexivos.

El autor hace hincapié en el potencial de la imagen reflexiva, proyecto hermenéutico, el cual, a través de un proceso didáctico y estético, revela los mecanismos por los que se construye la imagen, a diferencia de la imagen ilustrativa que esconde este tipo de mecanismos para ir a buscar cierta objetividad.

La complejidad de las imágenes (artísticas o no) incluye lo real, lo imaginario, lo simbólico e ideológico, y forma "constelaciones de significados" donde es posible "perseguir indefinidamente en el sentido del sujeto o de lo social" (Catalá, 2011: 89). Así que "ser receptor o usuario de una imagen significa iniciar un juego entre la identidad social e individual" (p. 19). Vale la pena entender las producciones simbólicas pensando el lenguaje como algo social y cultural, fruto del imaginario colectivo, teniendo en cuenta que la lectura e interpretación del mensaje depende de la multiplicidad de los mecanismos implicados en las imagenes -"sociales, subjetivos, estéticos, antropológicos y tecnológicos, etc."(p. 20)-, lo que nos permite comprender la imagen y lo visual. Pensando la complejidad contemporánea, Català creó el concepto de imagen compleja, aquí traducido por Buitoni:

"La imagen compleja rompe el mimético de enlace que la imagen tenía tradicionalmente con la realidad, sustituyéndolo por un vínculo hermenéutico: en lugar de una epistemología de la reflexión, se propone una epistemología de la investigación. La imagen ya no acepta pasivamente lo real, sino que va en su búsqueda, pero eso no significa que rechace la posibilidad de encontrar una objetividad pendiente de su descubrimiento: una realidad que tiene que ser hallada. Esto no quiere decir que la imagen, la visualización, sea un simple instrumento constructor de lo real; indica que lo real, para ser verdaderamente significativo, debe ser descubierto y que la visualización compleja es una manera efectiva de hacerlo" (Buitoni, 2010: 16).

Además de describir, interpretar la imagen y establecer su contexto, Català sugiere:

"Uno debe preguntarse dónde va la imagen. No se trata sólo de comprender cómo se compone la imagen (su estructura), sino también de cuales de los elementos y materiales que la componen no están conectados directamente a su mecanismo representativo, a su funcionalidad -qué mezcla, hibridación, deseos, e impulsos despierta-. Así, penetramos la imagen más allá de su superficie y rastrear los cables que conectan la imagen con otras 
imágenes y aspectos. Así, entramos en la imagen, vamos más allá de la superficie y descubrimos su sustrato inconsciente que la desliga del contexto inmediato al que pertenece" (Catalá, 2011: 35).

Catalá propone ir más allá de la información estricta de la imagen, para cuya comunicación fue creada, y descubrir en ella "secretos que nadie trató de expresar cuando fue confeccionada y que nadie realmente espera recibir, pero que están en ella", que diga hacia dónde va, "porque no hay un significado preciso que inmovilice el tiempo, pero tiene un alcance mucho más amplio".

Buitoni (2012: 74-76) explica que las imágenes complejas denuncian sus propios dispositivos, alteran el enfoque subjetivo/objetivo "proporcionando conocimientos, interpretaciones y digresiones, en fin, despertares estéticos que exceden la referencialidad de los documentales convencionales", expresando "su particular fenomenología y los problemas epistemológicos, cognitivos y estéticos que plantean".

La facilidad de registro y reproducción y los principios de eficiencia económica distancian el periodismo de la utilización de las potencialidades de la imagen compleja -la complejidad visual- que, según Català, "surge de la arquitectura que combina lo interno y lo externo, lo fijo y lo móvil, el espacio y tiempo, lo subjetivo y lo objetivo". "La imagen compleja, pues, no es mimética ni ilustrativa, es interactiva, interroga la dualidad entre el arte y la ciencia, y enriquece la comprensión de la realidad" (en Buitoni, 2010: 15).

Una mirada compleja en la imagen supera la "visión epidérmica" que predomina en los medios de comunicación. Según la Buitoni, Català propone investigar no sólo el camino a través del cual se puede reflexionar visualmente en este conocimiento: "[...] una imagen que no sea simplemente la ilustración de conocimientos expresado a través del lenguaje, pero que junto con ella, se convierta en cogestora de este conocimiento" (Buitoni, 2010: 15):

"Para Català, la imagen tradicional relacionada con la ciencia y la objetividad, es transparente, mimética, ilustrativa y espectacular (espectáculo que viene desde el Renacimiento, cuando la pintura servía para deslumbrar la demanda de observadores privilegiados). En contraste, la imagen compleja, a través de la afluencia de arte y la subjetividad, es opaca, positiva, reflexiva e interactiva. La imagen compleja construye una nueva objetividad científica posterior a la visualidad y que implica la deconstrucción de la objetividad científica convencional" (en Buitoni, 2012: 75).

La imagen compleja puede fomentar un diálogo sobre la realidad, superando el monólogo de los medios de comunicación, y cuestionar la hegemonía y la dominación. Considera la importancia de los medios (Tecnoindustrial ecología estética), pero ya no se basa en la tríada emisor-código-receptor, ya que presupone la existencia de un diálogo y no un código que separa los temas. Como dijimos anteriormente (Barros, 1998: 44), partimos del contexto sociocultural de la comunicación, haciendo hincapié en las mediaciones socioculturales, y, como dice Jesús Martín-Barbero (1997), en el establecimiento de vínculos con la hermenéutica. Lejos de limitarse al debate político, se invierte "en la identificación de casos de importancia en la comprensión de la pro- 
ducción de sentido". Se está cambiando la atención del objeto de la percepción estética e informativa, que tiene la propiedad de discurso de los medios y la producción de sentido. Desde esta perspectiva, la imagen compleja se presta a una condición de experiencia estética.

Como se argumenta en otro artículo (Barros 2012: 2-8), la experiencia estética, que es perceptiva, se desarrolla en la experiencia poética de articular sujeto y objeto como "instancias interdependientes", siendo el espectador la condición activa de significados productores, donde el trabajo se convierte en un proceso de objeto estético. Se le da sentido a través de un disfrute del espectador, que se apropia de ella y la socializa en una dimensión colectiva y cultural, lo que nos lleva a pensar en la experiencia estética en el contexto social en el que se vive. "La producción de significados, extrapola, así, una dimensión sintáctico- semántico, y es parte de un nivel semánticopragmático", partiendo del texto a la acción, como dice Paul Ricoeur. El concepto de "audiencia" manipulada por el aparato mediático, "recipiente de meras acciones de comunicación" da paso a la recreación de la obra. Por lo tanto, en los procesos de recepción y de experiencia estética, la producción de nuevos discursos genera significados e interpretaciones en un proceso dialógico y dialéctico, donde, en lugar de la convergencia, el consenso y la armonía, prevalecen las negociaciones, las pérdidas y ganancias en las hibridaciones.

El desarrollo de los sentidos, más allá del objeto estético (la percepción estética) que alcanza el campo de la interpretación (relación dialéctica, polisémico), se articula con el concepto de la imagen compleja y se relaciona con el concepto de obra abierta. Umberto Eco (1976), establece que la experiencia estética no se limita a la obra, pues esta es percepción estética y objeto estético a la vez. La imagen compleja se concibe como un espacio en el que se revela la verdadera hermenéutica fenomenológica y se profundiza el significado, la construcción del conocimiento. Al articular imagen y pensamiento, Català no se limita a reflejar lo real. Más allá de la comprensión de la imagen, sugiere la construcción del conocimiento a través de ella, donde lo visible revela las dimensiones ocultas de la real (Catalá, 2005: 37).

El autor sugiere el uso de imágenes complejas con el fin de aumentar su potencial. "La comunicación contemporánea exige nuevas formas de representación, capaces de establecer mapas complejos de las nuevas realidades. Estos mapas sólo pueden surgir de las posibilidades expresivas de la imagen", dice Buitoni (2010: 15).

El marco teórico proporciona elementos para investigar el potencial complejo y hermenéutico de la imagen en la prensa contemporánea. Nos ayuda a evaluar las influencias del arte en el periodismo. ¿Qué contribución puede aportar la imagen a un nuevo quehacer periodístico? ¿Cómo la prensa puede acercarse a nuevas formas de hacer arte a partir de una narrativa poética y una estética híbrida?. La imagen es comunicación y tiene el poder de la reflexión del arte y de ver en los productos culturales iniciativas que permitan una mayor apertura/participación del público en el proceso de comunicación pública. 


\section{Referencias bibliográficas}

BARROS, Laan Mendes de (1998): Experiência Estética e Experiência Poética: a questão da produção de sentidos. Disponible en: www.compos.org.br

BARROS, Laan Mendes de (2012): "Cultura das mídias e mediações culturais". En: BARROS, Laan Mendes de \& KÜNSCH, Dimas (Orgs): Comunicação: saber, arte ou ciência? São Paulo, Plêiade, pp. 127-151.

BENJAMIN, Walter (1990): “A obra de arte na era de sua reprodutibilidade técnica. 1935/1936”. En: LIMA, Luiz Costa (org): Teoria da Cultura de Massa. $4^{\text {a }}$ ed., Rio de Janeiro, Paz e Terra.

BUITONI, Dulcília Schroeder (2013): O registro imagético do mundo: jornalismo, embrião narrativo e imagem complexa. Rio de Janeiro, Compós. En: http://compos.com.puc-rio.br/media/gt8_dulcilia_buitoni.pdf

BUITONI, Dulcília Schroeder (2012): "Imagens contemporâneas: complexidades e interfaces". Revista Líbero, v. 15, n. 29, jun, pp. 71-89, São Paulo. En: http://www.casperlibero.edu.br/rep_arquivos/2012/08/20/1345493786.pdf [Acesso: 12 de janeiro de 2013].

CATALÀ, Josep M. (2011): A forma do real: introdução aos estudos visuais. [Trad. Lizandra Magon de Almeida]. São Paulo, Summus.

ECO, Umberto (1976): Obra Aberta. São Paulo, Perspectiva.

GARCÍA CANCLINI, Nestor (2002): Culturas Hibridas: Estratégias para Entrar e Sair da Modernidade. [Trad. Heloísa Pezza Cintrão, Ana Regina Lessa]. Ensaios Latino-americanos, $2^{a}$ ed. São Paulo, Editora da Universidade de São Paulo.

MACHADO, Arlindo (2004): “Arte e mídia: aproximações e distinções". Revista eletrônica e-compós, $\mathrm{n}^{\circ}$ 1. Dezembro. En: http://www.compos.org.br/e-compos [Acesso: 12 de septiembre]

MANNARINO, Ana de Gusmão (2006): "A reforma do Jornal do Brasil". En: Amílcar de Castro e a página neoconcreta. Dissertação de mestrado. Rio de Janeiro, Pontifícia Universidade Católica do Rio de Janeiro, pp. 3-58. En: http://www2.dbd.puc-rio.br/pergamum/tesesabertas/0410535_06_cap_03.pdf [Acesso: 14 de octubre de 2012].

MARTÍN-BARBERO, Jesús (1997): Dos meios às mediações. Rio de Janeiro, UFRJ.

NAKATA, Milton Koji (2010): “A Evolução da ilustração; concepções técnicas e tecnológicas". En: Série Póeticas Visuais: Arte \& Tecnologia, v. 1, pp. 70-83. NICOLA, Ricardo \& SALZEDAS, Neyze (orgs). Bauru, FAAC/Unesp.

SANTAELLA, Lúcia (2007): "Linguagens líquidas na era da mobilidade". Coleção Questões Fundamentais da Comunicação. Coord. Valdir José de Castro. $3^{\text {a }}$ edição. São Paulo: Paulus. 